\title{
Challenges Faced by The Recovered Youth Drug Addicts in Their Normal Lives: An Exploratory Study in Darjeeling District of West Bengal, India
}

\author{
${ }^{* 1}$ Anmol Lama and 2Dr. Sasmita Patel \\ ${ }^{1}$ Research Scholar at Department of Social Work, Visva-Bharati (A Central University), Santiniketan, West Bengal, India \\ 2 Assistant Professor at Department of Social Work, Visva-Bharati (A Central University), Santiniketan, West Bengal, India
}

\begin{abstract}
Addiction has been a big worry in our society in recent years because of its complicated nature, which frequently resembles a chronic disease that affects both the brain and the body. Drug addiction is common among youth who are unable to cope with modern society's rules. Simultaneously, some kids are seeking help from various specialists, to come out clean. However, the problem for them does not end there, they may have difficulties resettling into normal life. They may be having trouble dealing with a traumatic experience that is holding them back or having trouble establishing a routine to reestablish normalcy or find work, among other things.

The data for this qualitative study was collected using a semi-structured interview schedule as a tool and a Case study as a technique. Researchers used in-depth interviews to study and explore the multi-faceted challenges faced by recovered drug addicts in their normal lives after leaving rehab, as well as to understand the perception of drug addiction after recovery, its effect, causes, and other leading factors, with a focus on physical, spiritual, psychosocial, and socioeconomic challenges. Data were gathered from both primary and secondary sources. The study's primary respondents were ten cases who are recovered youth drug addicts between the ages of 20 and 34, who had completed their recovery and we're now living a normal life.

As per findings, individuals have little awareness of drug addiction and have a preconception about drugs and drug addiction before consuming drugs. As a result of peer pressure, curiosity, abusive households, and other factors, the majority of them become addicts throughout adolescence and come from good socioeconomic situations, making narcotics easily accessible. The findings indicate that, after recovery, they mostly deal with society's stigma toward recovered addicts, which leads to overthinking and inability to keep sobriety, as well as failing to find inner selves and purpose in life.
\end{abstract}

Keywords: Recovered youth drug addict, Drug addiction, Rehabilitation, Normal life

\section{Article Publication}

Published Online: 20-Jan-2022

\section{*Author's Correspondence}

\section{Anmol Lama}

9 Research Scholar at Department of Social Work, Visva-Bharati (A Central University), Santiniketan, West Bengal, India

\section{doi $10.31305 /$ rrijm.2022.v07.i01.003}

$\triangle$ findanmollama[at]gmail.com

(C) 2022The Authors. Published by RESEARCH REVIEW International Journal of Multidisciplinary.This is an open access article under the CC BY-

NC-ND license

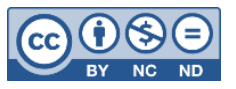

(https://creativecommons.org/licenses/ by-nc-nd/4.0/)

\section{Introduction}

Addiction is a complex, often chronic disease that affects the functioning of the brain and body while also wreaking havoc on families' relationships, schools, workplaces, and neighborhoods. Due to the competitive nature of today's society, youth have failed to balance their lives and have not been afraid to experiment with a drug that has become a prevalent part of a rite of passage for young people. They are responding to the alluring promise of today's chemical culture as a single body or as a group. Which appear to be a quick fix and instant gratification, popularity, and a desirable peer group. The majority of drug-using youth are those who have been unable to adapt to modern societal norms. However, a few youngsters only use drugs because of coercion or because they are intrigued about drugs.

Darjeeling attracts most national and international tourists due to its inherent beauty and famous tea gardens. This small district shares borders with other foreign nations and several state borders, creating Darjeeling a geographically strategic location and the only gateway to India's northeastern state. Darjeeling became the summer 
capital after the British arrived, and it eventually changed into a major trading center with the introduction of tea and cinchona plantations. It helps this small town grow in every direction and attracts people from all regions. Which lures migrants, and these people take over businesses. Darjeeling has become a tourism destination and has been merged into the wider global picture. These exposures to the outside world bring a lot of social and economic development, but they often have some bad repercussions. One of them is drugs; increasing movement of drug traffickers with illegal drugs from surrounding international borders, which renders substances easily accessible to youngsters, culminating in drug abuse. The recent years witnessed large-scale migration among them, and also unemployment, political agitation, and other fallouts which have resulted in the introduction of a new type of drug or substance, and also various new methods to consume drugs.

According to The Telegraph, (Siliguri, June 26, 2007), a survey was conducted in two locations in the Darjeeling district with the assistance of Quest Asia, a research and consultancy firm. A total of 250 injecting drug users were tested at each of these locations, demonstrating the growing number of drug abusers. Another study conducted by the West Bengal Prevention and Control Society (December 2006), indicated that up to 10\% of injection drug users in the Siliguri region are HIV positive. According to an Epidemiological Survey in the district commissioned by West Bengal State AIDS Prevention and Control Society, the prevalence of HIV among IDUs in three hill subdivisions of Darjeeling, Kalimpong, and Kurseong is 13.05 percent compared to Siliguri's $8 \%$. According to a 2015 Narcotics Control Bureau report, the country seizes approximately 3 tonnes of hashish (a mood-altering substance) each year. Officers from the Customs, Prevention and Intelligence Unit in Siliguri intercepted two parcels and seized $5.960 \mathrm{~kg}$ of hashish in Darjeeling in early 2015.

For many youths, drugs have become a popular means of escaping. At the same time, some youths are receiving assistance from various professionals including rehabilitation centers, psychiatric centers, guidance counselors, etc., guiding them to complete their course duration and come out clean. Their problems do not end during their addiction and recovery process or when they leave the treatment center. However, dealing with the social challenges in their normal social life after recovery is a major challenge for them. Addicts may face a variety of difficulties in coping with their surroundings, society, or relationships, including family, marriage, education, employment, health, personality, and financial concerns. After treatment, an addict may have difficulty accepting themselves for who they are, finding spiritual and emotional balance difficult, or finding it difficult to care for themselves in difficult times. They may struggle with how to deal with a traumatic event that is holding them back, which is also a reason for relapse for a recovered drug addict, or they may struggle with creating a routine to establish normalcy or to get a job, among other stuff. Trauma can have a long-term impact on body chemistry, influencing how people perceive themselves and their surroundings. Therefore, in this paper, the authors place their primary research with the objectives to find out what a recovered youth drug addict's normal life is like focusing on some of the components or challenges they face, perception on drug after leaving the treatment center, and how they deal with problems in various situations without the use of any substances.

\section{Review of Literature}

A thematic review of literature is presented for a better understanding of the issue under discussion in line with the research objectives.

\section{A. Factors Leading to Drug Addiction}

Shukla (2011) expresses his concern about the recent increase in drug abuse among young people (17-24 years) in his study "Increasing drug abuse among youth, symptoms, and solution". He outlines some of the factors that contribute to young people becoming addicted to drugs in his study. According to him, a variety of factors may be contributing to the rise in drug abuse, including the pressure of a competitive educational system that lacks flexibility, parental pressure on children to succeed academically, peer pressure, or, in some cases, a family problem. Shukla stated that in these modern times, where new technologies make life easier, society and institutions are also evolving by establishing new norms, systems, and so on. In which the majority of people adjust to these societal norms/systems, but some people struggle to find a balance in this system. School/college students are the most affected because these societal systems/norms may be opportunities for some students to 
achieve their goals, but they may be a challenge for others; as a result, they fail to compete with others and turn to drugs to escape. Other factors, such as wanting to fit in with their peers or being curious, have led to substance abuse among many teenagers.

Johnson (2018), in his article on "Drug Addiction Causes", was published on Casa Palmer's official website. Drug addiction results in uncontrollable behaviors and the inability to control one's use of meditation, alcohol, cigarettes, and drugs, whether legal or illegal. A variety of factors can contribute to drug addiction. The factors that contribute to drug addiction are genetics and the environment. According to the National Institute of Health, "about half of all drug and alcohol addictions are genetically determined." Three genetic factors influence a person's proclivity to engage in certain behaviors. All of these factors influence behavior, including capability (a person's psychological or physical ability to engage in the behavior), motivation (both automatic reflective mental processes that guide behavior), and opportunity ( physical and social factor in your environment). Drug addiction is influenced by a variety of factors, including a lack of social support, peer drug use, socioeconomic status, stress and the ability to cope with it, a history of abuse or neglect family, and others. Addiction, he explains, affects certain nerve cells in the brain, altering how it perceives pleasure. Drug addicts are more vulnerable than those suffering from other illnesses. Overall, the more risk factors a person has, the more likely they are to develop a drug addiction; conversely, the more protective factors they have, the less likely they are to develop a drug addiction.

Tracy (2012), in her article titled "Drug Abuse Cause: What Is the Cause of Drug Abuse?" was published in Healthy Places. The article focuses on co-occurring disorders and a variety of factors that lead to drug abuse. Suggestions that genetics is one of the causes of drug abuse, as well as the fact that drug abuse runs in families and can affect a child at any age, including adulthood. Environmental variables, certain life conditions, especially among younger users, parental abuse and neglect, pre-adolescents seeking parental attention or avoiding maltreatment, and other factors can all contribute to drug dependence. Drug addiction is exacerbated by an unstable family environment, which frequently leads to drug usage or mental illness in parents, as well as a strained connection with parents. Elders' and friends' drug use, permissive attitude toward their own adolescent's drug use, behavioral problem combined with poor parenting, and drug availability from a friend. When a patient with a depressed mood uses a drug to escape, but depression isn't the cause of drug abuse, it's only a contributing factor, it's referred to as a co-occurring condition. In the long run, genetic and environmental factors are not the primary causes of drug abuse; however, co-occurring conditions and drug combinations may be the most common reasons for people to become addicted to a drug. Tracy believes that co-occurring conditions and drug combinations are the most common causes of drug addiction.

Jedrzejczak (2005) published an article in Military Medicine on the title "Family and Environment Factor Addiction among Young Recruits". The study involved 559 subjects/recruits who had to pass a medical exam before joining the army. The results reveal a direct link between family dysfunction and drug addiction, with drug addiction, typically arising from poorly functioning and pathological families. In family alcoholism, the main factors are the family atmosphere, the strength of family ties, the sense of family happiness, and the structure of authority. According to the study's findings, 54.4 percent of young people are exposed to drugs while under the supervision of their mother rather than their father (22.6 percent ). 55.6 percent of recruits thought their father didn't spend enough time with them. Only $33 \%$ of the recruits studied come from a family without a history of narcoma. Young people's use of psychoactive substances is influenced by the strength of their family ties as well as their emotionality. Large cities and families with a history of addiction have the highest rates of drug use.

\section{B. Their Perception on Drug Addiction}

Faria E. A., et.al. (2015) conducted a study on "Perception of Adolescent Student about Drugs" to understand the living with drugs, opinions, beliefs, and attitudes toward drug use. They discovered that students' superficial knowledge of the drug was revealed in the first category and that drug use means disease, crime, or immorality. The habit of drug use, particularly by a family member such as parents, siblings, or relatives, falls into the second category, in addition to contributing to early commencement of use. The third set of categories consists of Peer pressure, social rules, and influences that influence the majority of naturally curious adolescents. Most students 
believe that drug addiction is caused by negative peer pressure and that the best way to avoid drug addiction is to stay away from the addicted person. They discovered that adolescent students are aware of drugs and associate their use with delinquent and criminal behavior.

Another study was published by Hyde, A., et al. (2000) on the title "Young People's Perception of and Experience with a Drug: Finding from an Irish Study". They divided the children's drug knowledge, awareness of drug use in their social environment, drug experiences, and knowledge into conceptual themes. The majority of children were unable to name drugs, but they all mentioned an illegal substance. The majority of those in the second group learned about drugs from relatives, family members, and other sources. The majority of children were exposed to drugs in a variety of ways, including seeing drug users' evidence. Adolescents are exposed to drugs through witnessing drug dealing, and those who participate, particularly those who smoke cannabis, are exposed to drugs through curiosity. Children appear to be afraid of talking to adults about their drug dealing experiences, which will limit their ability to develop refusal skills. The kids also seem to understand some of the negative consequences of drug misuse. The drug had some health and social effects, according to children's accounts. The study also discovered several mental, physical, and other consequences, including the loss of family, the financial cost of buying drugs, being arrested, ruining one's life, and so on. As a result, the study discovered that the substance a child consumes is generally consistent with established views on the issue, and is at odds with any notion that children regard consuming as acceptable or normal since the prevalent drug-taking discourse to which the youngsters were exposed is anti-illegal drug use.

\section{Challenges Faced in Their Normal Life}

An article on "Common Challenges After a Successful Recovery" was published by The Right Step Treatment Center (2017, July 27). It has been mentioned that it's natural to feel uncertain and overwhelmed after a successful recovery. Many people who have recovered face a variety of challenges, including social challenges that require them to surround themselves with non-drug user friends, protect their sobriety, and form friendships with people who respect and support them when they are tempted to relapse. The financial crisis is a difficult situation for recovered addicts, and it may lead to relapse. The risk of relapse exists even after successful treatment. Overdose is one of the most serious dangers they face, as many relapse addicts use too much substance and overdose because their bodies are no longer accustomed to high doses. Either a coma or death resulted as a result of this.

Meghan (2016), in his article on "Dealing With Boredom and Other Challenges in Early Recovery", stated that the problems in addicts' lives do not end after treatment. She mentioned that they will instead be confronted with situations or people that may prompt them to use the drug again. As a result, people either avoid or prepare for such situations. Relapse is easily caused by people, places, and things associated with drugs, as well as old peer group pressure. She considers avoiding bars to be a no-brainer. If the person is a former alcoholic, certain places must be avoided. These places can trigger feelings and emotions associated with drinking or getting high, even if there is no indentation of relapse. In terms of other triggers, it's critical to remove anything prominent during the addict's active addiction; these items shouldn't be present to mistakenly glorify the addiction.

Laudet A. B., et al.(2000) conducted a study on "Recovery Challenges Among Dually Diagnosed Individuals" with participants at Double Trouble in Recovery (DTR) in New York City. DTR is a mutual aid program based on the alcoholic's anonymous 12-step program (AA). Participants' socio-demographic and background information, mental health status and history, the stigma associated with having a dual illness, recovery problems, history, and experience were all examined in this study. Dealing with feelings, finding or keeping a job, financial crises, boredom, feeling helpless, dealing with medication, being open-minded, and so on are among the 29 recovery challenges listed. The challenges faced by 46 percent of participants ranged from very difficult to very stressful in dealing with feelings and working, 15 percent of participants were following a program such as 12 steps to deal with different situations, and 13 percent were accepting higher power or taking responsibility," according to the study's findings. 


\section{Socio Economic Factor}

Ahad, M.A., et al. (2017) conducted a study on "Socioeconomic Status of Young Drug Addicts in Sylhet City, Bangladesh" which focussed on how drug addicts' socioeconomic characteristics influence their daily lives, as well as the relationship between drug addiction characteristics like age, religion, education level, occupational status, marital status, family size, and the addict's residence, among others. They discovered in this study that youth who live in an extended family $(66 \%)$ and have their own home are more likely to be addicted because they can easily obtain money. They also discovered that 14 of the 42 drug addicts were unemployed, with an age range of 18 to 37.30.81 percent having completed primary school and 39.34 percent having completed secondary school. 57.14 percent were unmarried drug users, 40.48 percent of the family head were father drug users. They further claimed that most Bangladeshi young are addicted to "cannabis" and "yabba" since these drugs are readily available in local marketplaces and, are less expensive to purchase than synthetic narcotics.

Janicijevic K.M., et al.(2017), conducted a study in Serbia on "The Socioeconomic Aspects Linked to Adolescent Psychoactive Substance Abuse". The study focussed on the family's socioeconomic status, which is frequently linked to adolescent drug use. For this study, they analyzed data on respondents aged 15-24 years, 51 percent of whom were women, to identify risk and protective factors associated with the psychoactive substance. Members aged 20 to 24 are more likely than those aged 15 to 19 to consume alcohol. People with higher education are 55.3 times more likely to become alcoholics than those with a lower degree. A young person who lives in an urban area is 1.8 times more likely than those who live in a rural area to consume alcohol as a reaction. Young people who are subjected to physical violence and bullying on a physical, mental, or emotional level are significantly more likely to consume alcohol.

An article published in the Delhi Psychiatry Journal on the "Socio-Cultural Aspects of Adolescent Drug Abuse" byJilohaR.C.,(2009), discussed several factors that chip into the initiation and maintenance of drug abuse in adolescents. He claims that smoking is more prevalent in families with low socioeconomic status than in families with a higher level of parental education and socioeconomic status. The reason for this is that children from low socioeconomic backgrounds who work in low-level jobs and have an unstable family income, as well as material disorder, divorce among parents, and single parenting, are linked to adolescent drug abuse. Another reason for drug abuse is the easy availability of local products such as "beady," illegally prepared local liquor, and other similar items at low prices and in convenient locations for low-income families. the majority of drug-abusing children are street kids, school dropouts, and unskilled laborers engaged in rap picking, rickshaw loading, and unloading of goods. In the conclusion of this article, the author stated that addiction affects people regardless of their socioeconomic status.

However, in developing countries such as India, people from low socioeconomic or below poverty line families are also becoming addicted to drugs and alcohol due to the easy availability of local substances at low prices.

The present research work is based on the gaps found in the review of the literature. It was seen that there has been much research on the subject but none of them talked about their spiritual being of defining themselves, very few attempted to explore their perception on drug after recovery, and especially very few attempted to understand the difficulties after recovery during their recovered normal life. But, non of the researchers have tried to focus on the cases of Darjeeling being a vulnerable district because of the above-stated reasons. Thus, the researchers undertook the current research work in the line with the defined objectives.

\section{Objectives of the Study}

- To study the socio-economic background of recovered youth drug addicts.

- To analyze various factors leading to drug addiction among the recovered youth drug addicts their perception on drug addiction.

- To understand various challenges faced by recovered youth drug addicts in their social life. 


\section{Methods and Materials}

The proposed study is based on purely qualitative research and has primarily followed an exploratory research design. The researchers expounded on the perception of young recovered drug addicts on drug addiction, factors leading to drug addiction, and the challenges they face assimilating them into their normal social life. They too described the socio-economic background of the young adults to have a proper understanding of the various socio-economic dynamics which underplay behind drug addiction. The researchers have adopted the Case study method and taken ten cases for the research. They have used a Semi-structured Interview Schedule for the indepth interviews. All the cases were young recovered drug addicts between the ages of 20 and 34, who had completed their recovery process and now living their normal life in their families. The cases are from various parts of Darjeeling and are linked with the rehab institution Kripa Foundation situated at Darjeeling. The respondents had recovered, have been continuing follow-up programs provided by the center, and had begun to live their lives outside of the rehabilitation center i.e. with their families in their respective communities.

\section{Finding}

The summary of the findings will be discussed in a sequence of the objective of the study.

\section{Socio-Economic background of the respondents}

The researcher also attempts to comprehend the socioeconomic background of the recovered drug addict youth in this study. Age, family income, mother and father occupations, number of families, marital status, religion, and qualification are the characteristics of the respondents for this study. The researcher conducted Case studies of 10 recovered youth drug users, the majority of whom were between the ages of 19 and 34, with a mean age of 27. It is to be noted that the cases interviewed were just recovered and had begun to live their lives outside of the rehabilitation center, making it easier to comprehend the respondent's perspective and influence. The respondents came from various parts of the Darjeeling district and their names are changed to kept confidentiality.

Aditya Gurungis a 20-year-old recovered drug user who lives with his parents. His family consists of four members, including his mother, father, and younger brother, and they live in one of Darjeeling's tea estates and they follow the Hindu religion. He is the son of a retired army personal, and his mother is a housewife. His family relies on his father's pension after retirement, and their monthly income ranges from 30,000 to 45000 rupees. He became an addict as a result of his father's strictness, as well as peer pressure and curiosity. He claims that he is still unemployed after his recovery because every time he applies for a job, he gets turned down due to his drug addiction background.

Kewal Tamang, 32, lives with his mother, wife, and daughters in a family of four. Before his addiction, he worked as a daily wage worker. His father used to be a private civil contractor, his mother is a schoolteacher, and his wife runs a small business in Darjeeling town and they follow the Buddhist religion. According to him, he became addicted to drugs after he saw his older brother using a drug at the age of 15 , and out of curiosity, he began using drugs. Before his recovery, he used to acquire some labor jobs because of his father's reputation, but he was fired from a job owing to his neglect at work due to his drug addiction. He shared his difficulties in getting work because of his past. However, he claims that he manages to find a job and assist his wife and mother in running their household and that their monthly family income ranges from 20,000 to 30,000 rupees.

Phurba Sherpa, who is 27 years old and lives in Darjeeling with his father and mother, is a Buddhist. He's finished his tenth standard. His father is a businessman and his mother works for the government, and their monthly salary ranges from 35,000 to 50,000 rupees. Following his rehabilitation, he is primarily reliant on his family for support. He claims that he wants to do the job and financially support his family, but he still believes that his family does not fully trust him, making him frightened of facing society.

Sumit Sebastian Rudum, 25, lives in Darjeeling with his father, mother, grandparents, brother, and sister. His father works as a clerk at a private firm, his mother is a housewife, and he has a bachelor's degree. His family is entirely reliant on his father's monthly earnings, which range from 10,000 to 15,000 rupees. He began using drugs 
at the age of 16 as a result of curiosity and peer pressure. He has had several challenges during his recovery because he has been dismissed twice from his job due to his drug use history.

Akhlesh Thami, who is 21 years old, lives with his mother, father, and younger sister in a Buddhist family. His father works as a truck driver, and his mother is a housewife. He has finished his tenth standard. His family is also entirely reliant on his father's monthly salary, which ranges from 7000 to 9000 rupees. He claims that he began drinking because his mother used to sell local alcohol in his home and that he eventually became addicted. He is unemployed after his recovery, but he wishes to resume his studies.

Saran Pardhan, 25 years old, lives with his father and mother and is a Hindu. He has completed his 12th standard. His father is a professional driver, while his mother works as an employee in a government agency. His family's monthly income ranges from 25000 to 35000 rupees. He became addicted to drugs as a result of his society's elder brothers, with whom he used to spend time. He spends time in the home after his recovery, helping his mother with household duties.

The 34-year-old Youchan Lama lives with his mother, father, wife, and two daughters and practices Buddhism. His father is a government employee, and his mother is a government teacher. His wife owns a small shop in the neighborhood, and their family income ranges from 90,000 to 1,00,000 rupees. He isn't sure when he started doing drugs, but it was due to peer pressure and curiosity. He believes that he relapsed twice because he struggled to find suitable employment after his recovery, prompting him to overthink and turn to narcotics to get through that period.

Bikash Sapkota, 30, lives with his father and mother and practices Hinduism. He was married, but his wife abandoned him; his father works for the government, and his mother is a housewife. His family is entirely reliant on his father's salary, which runs from 50,000 to 60,000 rupees every month. He began taking his substance when he was 16 years old. His older brother used to abuse drugs and died as a result of an overdose because he couldn't resist the trauma and started the drug. His family compelled him to marry because of this, but when his wife discovered him out with drugs, she left him. He tried to reclaim his wife after his recuperation, but she did not return, making him even more irresponsible and rejected.

Kunal Kharga, 30, lives with his mother, father, and grandma, all are Hindu by religion. He had been married, but his wife had abandoned him. He has completed his $12^{\text {th }}$ standard. His father worked as a government teacher, while his mother is a housewife. He used to work as a laborer before his recovery. His family is entirely reliant on his father's monthly wage, which ranges between 35000 and 40000 rupees. He claims that when he was a child, his grandmother drank alcohol before going to sleep, and he used to sip from them, not knowing when he became drug-addicted. He tries to find work after his recovery, but due to his record of addiction, he has difficulties. He also claims that his wife left him due to his irresponsibility as a result of his addiction.

Pravin Gurung, 29, is a Buddhist who lives with his mother and father. He was married, but his wife had deserted him. His mother is a housewife and his father is a government teacher. His family is entirely reliant on his father's monthly earnings, which range from 20000 to 35000 rupees. He claims that he lacked confidence in school and while interacting with people, so he began using drugs in modest doses to acquire confidence, but eventually developed an addiction. After his recovery, he began working in a small business and decided to take responsibility to bring his wife home.

It shows that the majority of the respondents have come from good socio-economic backgrounds families, making it easier for them to obtain narcotics. It was also explored that recovering drug users have a tough time regaining trust in their families and society after they have recovered. This caused individuals to struggle to find work and take on family responsibilities, which sometimes resulted in relapse.

\section{II.a.Understanding the Contributing Dynamics of Drug Addiction}

Youngsters become addicted to drugs for various reasons. Few have stated that their peer group has impacted their consumption of drugs. It has begun with a peer's influence and it later became a habit. Family strictness or issues in the family happens to be another reason for other respondents. Aditya said, “... my father was in the army 
and he used to be too strict for me and I thought drugs will give help me to deal with that strictness". AkleshThami shared, "I used to be a shy guy in school with very low confidence, and my father used to drink a lot and sometimes abuse my mother, so using drugs helps me forget all my anger and gives me confidence."

In both cases, the negative family environment has contributed to the addiction. Besides that, the majority of the respondents began using drugs in school due to poor self-esteem or lack of confidence. Of course, availability and access have been the prime factors of drug addiction at a young age. The findings of Ankur Shukla's 2011 discloses that the peer group effect is very strong in adolescence. An endeavor to become an active leader of a group often results in addiction for a boy or girl generally in groups where the other member(s) are into drugs and alcohol.

The environment influences behavior, as discussed in Casa, Palmer Staff's article by Johnson (2018) on Causes of Drug Addiction and Environment includes lack of social support, drug usage among peers, Parental and family involvement, socioeconomic status. These factors are also seen in the responses during the in-depth interviews. Some of the responses included that they like to spend time with the elders where elders used to smoke, cigarette, cannabis, and use a drug, which increased their curiosity and a feeling of social sanction about the drug, and they began to use as well.

\section{II.b. Take of the Youth Recovered Drug Addict on Drug Addiction}

Most of the respondents were aware that drugs are dangerous for health and that they had seen their elders' physical health worsen as a result of drug use, it many a time leads to death, due to overdose it creates health problems, and that it is not good for the society and should keep distance from drugs.

Bishal Sapkotaspoke, "I knew that it leads to death because I have seen my elder brother who was also a drug addict die because of overdose." According to Phurba, "drug addiction is the worst thing in a society, so I bave to keep my distance now from drugs and the people who consume drugs."

It appears that they had heard from many elder people in their society and locality that drugs are not good for health and society. The researchers deduce from the findings that the majority of the respondents had only a cursory understanding of drug addiction before taking the drug. Their research also reveals that the family members are well aware of many repercussions of drug addiction but it becomes almost impossible to counsel or handle the addicted at that time.

\section{Different Problems and Challenges Faced by Recovered Youth Drug Addict in Their Normal Life A. Physical Challenges in Normal Life}

According to the respondents, they had no physical concerns following their recuperation on whatever they faced at the time of drug consumption and the detoxification process. In fact, since returning home from the rehabilitation clinic, they have had no severe health problems. Aditya shared, "After returning home, the first two weeles were normal, but by the middle of the second week, my jaw had locked while eating, which usually happens while speaking; later on, my left-hand fingers also began to lock while doing some household work." Kunal Kharga expressed, "Sometimes my liver doesn't work properly and I have to rush to the doctor, and other times I have mild joint pain and back pain that gets worse in the winter." Pravin said," I love football and always wanted to play, but I couldn't play with my friend because of joint pain in my leg. I used to think about taking drugs to play football."

However, unlike Aditya, Kunal and Pravin many others experience small issues such as jaw and fingers locking while eating or conversing with others, joint pain and they experience internal issues such as liver discomfort or back pain as a result of past drug abuse history.

\section{B. Psychosocial Challenges in Normal Life}

Normal life for recovery is difficult since they still have a trust issue and sometimes feel that their family doesn't understand their thoughts due to a communication gap. They have suffered the consequences of society stereotyping which leads people to assess or evaluate them, invent an excuse not to hire them; this type of behavior makes them uncomfortable in society. One of the recovered drug addicts Kewal shared, "When I get home 
from rehab, I share whatever comes to mind with either my mother or my wife. They also respond positively." However, I felt even worse when I went back to my old workplace to look for work; they gave me various reasons not to keep me there. Such behavior makes me feel rejected." Bikash Sapkota expressed, "After my recovery, there have been many changes in my family, particularly in their behavior; however, there is still a communication gap between us; they are still unable to understand my thoughts, feelings, and so on, and I take this as a positive because they are trying for me."

When they return home to their normal lives, initially the majority of them feel at ease but later on, they start feeling alienated. They are often confronted with a difficult scenario as a result of rejection and irrelevant thought that fills their minds. They also experience boredom because there is no one to converse with at home. So, they hang out with siblings or friends to keep themselves occupied. In some cases, they keep themselves occupied by undertaking domestic chores. Sumit Sabestine said, "Before using drugs, I was shy and spent most of my time alone, which was also a reason for me to use drugs. Now, I spend lots of hours with my siblings; if they are not present, I spend time with my mother; however, negative thoughts still enter my mind regularly." AklashThami shared "I usually have irrelevant thoughts when I'm bored, so my parents do whatever they can to keep me occupied." When it is difficult to cope with the thought, I immediately contact the center, and they assist me in dealing with this type of thought."

Loneliness and boredom bring negative thoughts to the minds of many recovered youth drug addicts. Few keep themselves occupied by talking with mom, viewing television, or listening to music, among other things. Despite their best efforts to keep themselves occupied; these irrelevant ideas always put pressure on them in living a regular life. A case was terrified of relapsing after recovery because they believe they will be unable to confront the societal obstacles. One case got relapsed after his society began mocking him for being a drug addict. Another had a relapse after his wife abandoned him. Some people relapsed because they were unable to create a new acquaintance, and they began to spend time with their former drug-sharing companion again. Yonchen and Pravin have a similar fear of relapse as they shared, "I have a fear of relapse because of this addiction I have to live a lonely life, without my wife and family".

In the view of Aditya "Nobody says anything to me about my addiction problem, but I can tell by their behavior and attitude toward me from my villager that they still see me as a drug addict. I still struggle with forming new relationships after returning, and I still lack confidence. But I'm doing my best to make new friends, find a girlfriend, and repair an old relationship in my neighborhood without using any chemical substances." Yonchen Lama said, "After returning from recovery, some people continue to talk about me and my character; in the beginning, it matters to me a lot, and I used to drink a lot. But it no longer bothers me because I've begun to focus on doing something good for my family, my wife, and my daughter. However, I encountered some difficulties in repairing old relationships."

However, the researchers explored that the majority of the problems they confront in everyday life are caused by their overthinking about various situations, which leads to unrealistic and useless thoughts. Society's attitude toward them, or the support they expect from society, causes them to think in a way that makes every circumstance a challenge. Saran Pradhan stated, "I began using drugs after my society began mocking me for my drug addiction. So it became so troubling for me that I began abusing drugs."

According to an article on Common Challenges for Addicts by the Right Step, (2017, July 27), if a person wants to protect their sobriety, they must create friends who accept their resolve not to use drugs again and who will support them when the temptation to relapse strikes. Self-exploration is required by recovering drug addicts to find new hobbies, interests, and social groupings.

\section{Socio-Economic Challenges}

In half of the cases, they were able to easily obtain money from family members to purchase the substance. They have a hardship once they return home from the rehab facility in terms of taking responsibility and providing a stable life for their family. Bikash Sapkota said, "my wife refuses to return home because she knows I am incapable of shouldering the duty and providing her with a secure existence. He also added, "The cruel part is my society, I feel rejected because of them; for them, before recovery, I was a drug addict, and now, after recovery, I am still a drug addict for them, this causes me to overthink." Kunal Tamang expressed, "It is very difficult for me to take full socioeconomic responsibility for my family because it is too difficult to find a permanent job where people still believe I am a drug addict." 
Finding a job after returning becomes very difficult for them, and as a result, they face financial difficulties and rejection in the family and society as they cannot shoulder the family responsibilities. Similar issues were mentioned in the article on Common Addiction Challenges by the Right Step, (2017, July 27). Many recovering drug users discover that their financial condition is difficult and that they have limited resources once they have recovered. Later on, this could lead to overstress and become the primary reason for relapse. These issues make life difficult for a married recovering addict.

\section{Spiritual Challenges}

When asked about authentic self as a spiritual problem, the respondents were quite unsure whether they knew themselves or not. Some people stated that they are introverts by nature and don't know how to express themselves. Kunal Kharga said, "Yes, I've tried to know myself, but I'm still confused because when I thought I finally understood myself or had an authentic self, my body reacted differently and my mind said something else. One of the reasons I didn't know the purpose of my life, I felt isolated and empty at the family gathering because I was the only drug addict, so I assumed I would never match with them."

Few others also claimed they have no idea who they are since they have never tried. Many of them have avoided answering the question because they still struggle to be themselves, which is a difficult task for them. However, some of them expressed that they are putting their efforts into finding a greater purpose in their lives by doing all they had abandoned or missed throughout their drug addiction. Phurba expressed, "Now I still want to have a purpose in my life, but I feel emptiness or isolation when I try to do something in my life and fail because I don't have any educational qualifications, talent, or skills. After that, I always tried to isolate myself from others."

However, how much effort do they put out in dealing with difficult situations or challenges they feel isolated and lonely when a family member fails to understand them or when their thoughts and words do not match those of others during a family gathering. Saran Pradhan revealed, "I used to participate in some group activities because my mother encouraged me to do so, but after going there, I became irritated with most of the people because they began giving me drug addiction advice."

When people fail to find the correct route or good purpose in their lives, they feel alone and hollow. As per the findings, the majority of those who recovered gain awareness that there is another world outside of the chemical world where they may experience interconnectedness with all living creatures and seek self-knowledge, meaning, and purpose in their lives. Family and society play a major part in their lives in helping people to understand themselves. If a family does not know how to do so, they should request guidance from a rehab facility, a counselor, a social worker, etc.

\section{Conclusion}

It is considered taboo in a small town like Darjeeling, where people are uncomfortable talking about their young children being addicted. Despite the government and our society's best efforts, the majority of youngsters continue to fall prey to drug addiction. The current research focuses on rehabilitated youth drug users who are confronted with new difficulties in their daily lives being in their families.

The findings demonstrate that the majority of those who become addicted to drugs come from a good socioeconomic background, as a result, the drug is easily accessible and affordable for them. When it comes to perceptions about drug addiction before using the substance, many have no idea and have limited knowledge of the addiction. As a result, a majority of them developed an addiction, through different reasons like peer influence, curiosity, and influence from elders or abusive family members. Since drug addiction is so severe, most people experience a variety of obstacles once they recover, including economical, spiritual, physical, and emotional issues. The study discovered a major difficulty in this task, which is the respondent's overthinking and society's attitude or stereotype toward them, which causes them to have irrelevant thoughts. Other factors are abusive parents and lack of understanding of family members towards the person they are, which make it quite difficult for recovering youth to resume their normal social lives. They face many more psychosocial problems and the problems are in different areas of life, so they need support and counseling for those areas. 
The most serious issue in Darjeeling District is that most people are unaware of the true meaning of drug addiction. The government and rehabilitation centers must begin a prevention mode of operation by raising awareness at the village level. steps such as integrating substance abuse treatment into mainstream health care Individuals with substance use disorders of all severity levels will be a fantastic initiative to prevent addiction. However, integrating substance use disorder care into general health care will be impossible without a workforce that is cross-trained and educated in all of these areas.

\section{References}

Ahad, A., Chowdhury, M., Islam, B., Alam, F., (2017, June). Socioeconomic status of young drug addicts in Sylhet city, Bangladesh. IOSR Journal of humanities and social sciences, volume 22, issue6, ver.2 pp 84-91 DOI: 10.9790/08372206028491. Retrieved 2019 From (https://www.iosriournals.org/)

Boys, A., Marsden, J., Strang.J., (2001, August). Understanding reason for drug use amongst young people. A functional perspective, health education research, volume 16, issue 4, page 457-469.doi.org/10.1093/her/16.4.457 Retrieved 2019 From (https://academic.oup.com/her/article/16/4/457/)

Challenges to staying sober after rehab publish. (2018). Prosperity Haven. Retrieved 2019 From (https://www.prosperityhaven.com/challenges-to-staying-sober-after-rehab/)

Faria, E. A., Filho, Queiros, P. S, Medeiros, M., Rosso C. F. W., Maria M., De Souza M. M. (June 2015). Perception Of Adolescent Students About Drugs.Rev Bras Enferm.vol.68 no. 3 ,457-63,517-23, DOI: http://dx.doi.org/10.1590/0034-7167.2015680320i.Retrieved on 2019 from (https://www-scielobr.translate.goog/j/reben/a/TSfnNP63bcyZgpNpSSccttB/?lang=pt\&_x_tr_sl=pt\&_x_tr_tl=en\&_x_tr_hl=en\&_ x_tr_pto $=$ sc)

Janicijevic, K.M., Kocic, S.S., Radevic, S.R., Jovanovic, M.R., RadovanovicS.M.,(2017 June).Socioeconomic factors associated with psychoactive substance abuse by adolescents in Serbia.Front. Pharmacol. volume 8 article 366.doi: 10.3389/fphar.2017.00366. Retrieved 2019 From(https://www.frontiersin.org/articles/10.3389/fphar.2017.00366/full)

Jêdrzejczak, M., (2005, August). Family And Environment Factor Drug Addiction Among Young recruits.MilitaryMedicine, VOL.170, PAGE 8:688 http:// doi.org/10.7205/MILMED.170.8.688. Retrieved 2019 From (https://academic.oup.com/milmed/article/170/8/688/4577705)

Jiloha, R.C., (2009). Social and cultural aspect of drug abuse in an adolescent.Delbi Psychiatry Journal, pp 168-169. Retrieved 2019 From (https://silo.tips/download/social-and-cultural-aspects-of-drug-abuse-in-adolescents)

Johnson, J., (2018). Causes of drug addiction. Casa Palmer Staff. Retrieved 2019 From (https://casapalmera.com/blog/author/jeff/page/3/)

Knox, B., Santos, P., Whitaker, T., Treacy, M., Hyde, A., (2000). Young people's perception of and experience with a drug: finding from an Irish study.HEALTH EDUCATIONJOURNAL 59(2), PAGE 180 188, DOI:https://doi.org/10.1177\%2F001789690005900207.Retrieved 2019 from (https://www.drugsandalcohol.ie/6739/)

Laudet, A. B., Magura, S., Howard, S., Vogelc, S.W., Knight, E.,(2000). Recovery Challenges Among Dually Diagnosed Individual. Journal Of Substance Abuse Treatment, pp321-329. DOI: 10.1016/s0740-5472(99)00077-x. Retrieved 2019 From (https://www.sciencedirect.com/science/article/abs/pii/S074054729900077X\#!)

Meghan, (2016, September 29). Dealing With Boredom and Other Challenges in Early Recovery. Retrieved 2019 From (https://fherehab.com/news/dealing-with-boredom-and-other-challenges-in-early-recovery/)

Shukla, A, (2011). Increasing drug abuse among youth, symptoms, and solution. Retrieved 2019 From (https://www.youthkiawaaz.com/2011/07/increasing-drug-abuse-among-youth-symptoms-and-solutions/)

The Right Step, (2017, July 27). Common challenge addict faced successful drug rehab. Retrieved 2019 from (https://www.rightstep.com/rehab-blog/common-challenges-addicts-face-successful-drug-rehab/),

Tracy, N., (2012). Drug Abuse Causes: what is the cause of drug abuse? Healthy Place. Retrieved 2019 From (https://www.healthyplace.com/addictions/drug-addiction/causes-of-drug-addiction-what-causes-drug-addiction) 